
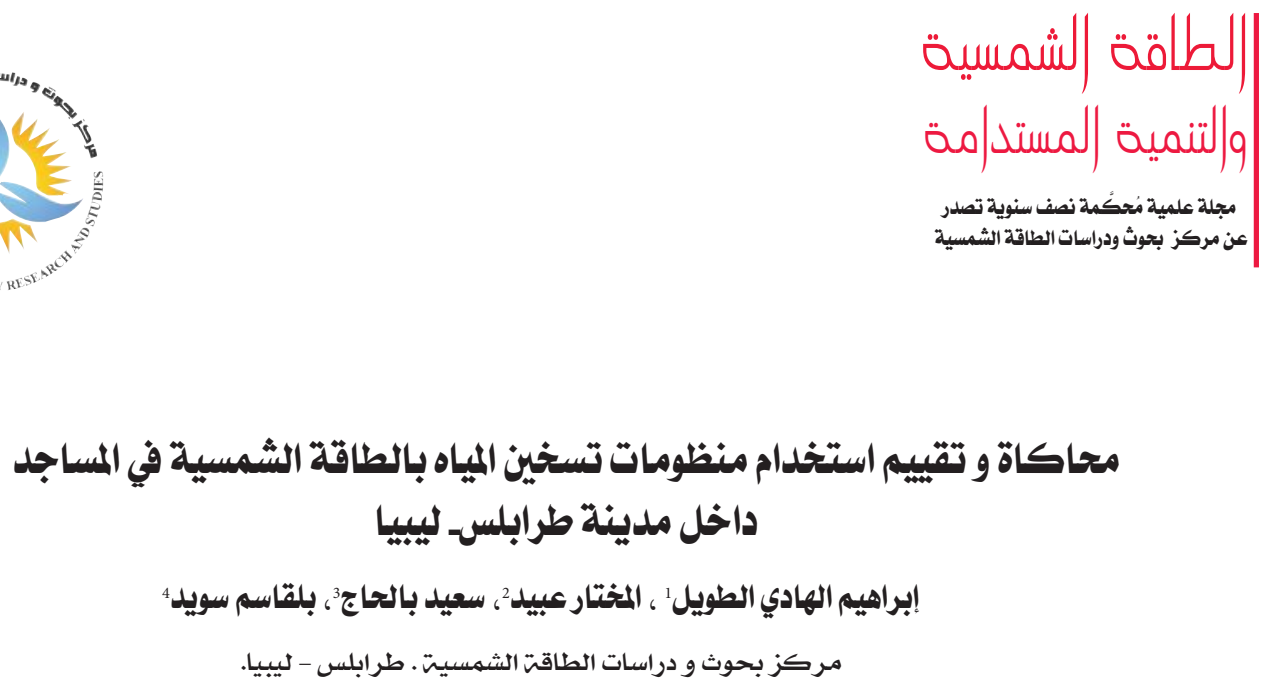

بريد إلكتروني:

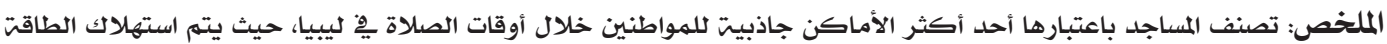

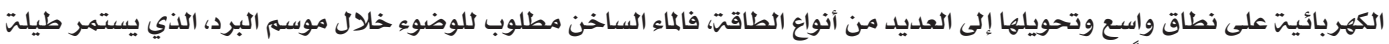

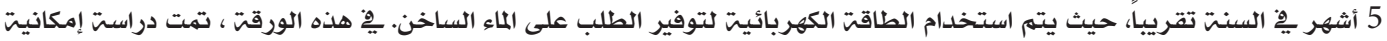

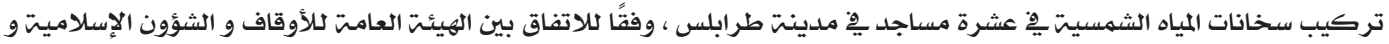

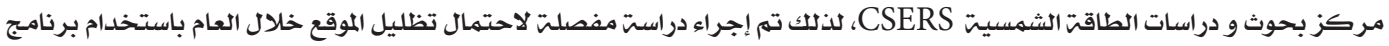

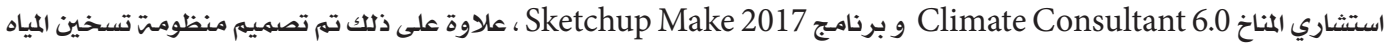

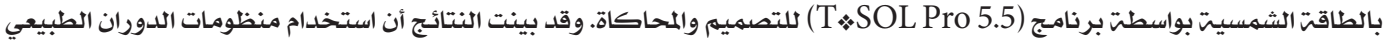

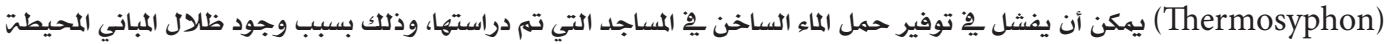

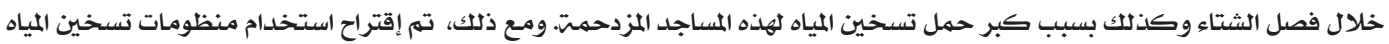

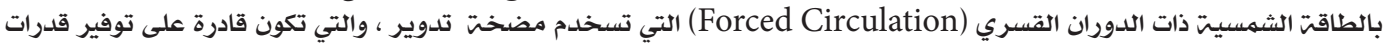

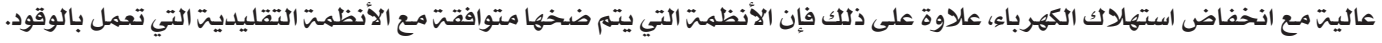

\title{
Simulation and Evaluation of Solar Water Heating Systems Availability in Mosques Sector in the City of Tripoli- Libya
}

\author{
Ibrahim H. Tawil, Mukhtar BenAbeid, Said Belhaj, Belgasim Sowid \\ Centre for Solar Energy Research and Studies, Tripoli, Libya
}

Abstract: Mosques are classified as one of the most attractive places for the Libyan people during
prayer times, where electrical power is consumed extensively and converted into many energy
types. Hot water is required for ablution during the cold season, which occupies 5 months per year,
approximately, where electrical power is utilized to provide hot water demand. In this paper, the
possibility of installing solar water heaters in ten mosques in the city of Tripoli is studied, according
to an agreement between the General Authority of Awqaf and Islamic Affairs and CSERS. Therefore,
a detailed study was performed for site shading probability during the year using Climate Consultant
6.0 software, and Sketchup Make 2017 . Furthermore, the solar water heating system was designed
by ( $T^{\star S O L}$ Pro 5.5 ) design and simulation software. The results have illustrated that employing 
thermosyphon systems could fail to fulfil water heating load in the studied mosques, due to the presence of the surrounding buildings shade during winter and the high water heating load of such crowded mosques. However, the present study suggests the use of central pumped solar water heating systems (forced circulation), which are able to provide high capacities with low electrical consumption. Moreover, the pumped systems are compatible with the conventional fuel powered systems.

Keywords: Solar water heating systems, Thermosyphone system, Forced Circulation, $T^{\star}$ SOL, Shading Study.

\section{1}

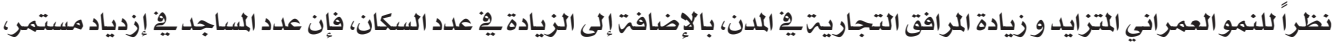

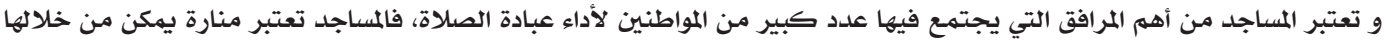

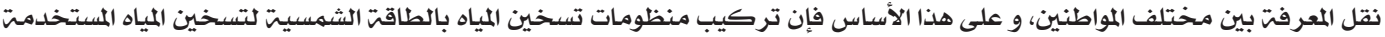

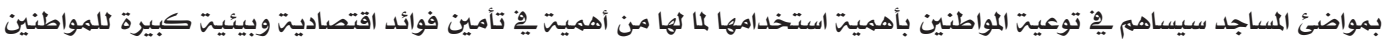

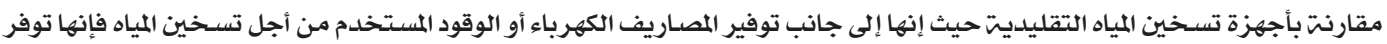

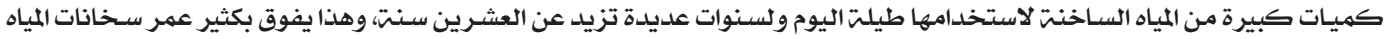

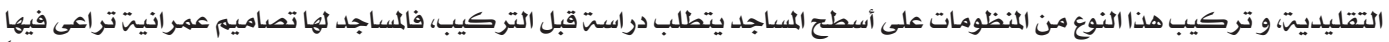

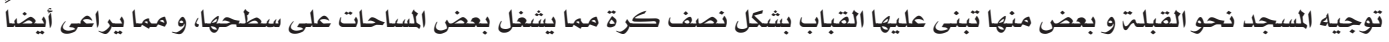

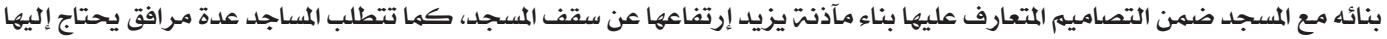

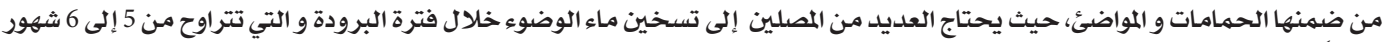

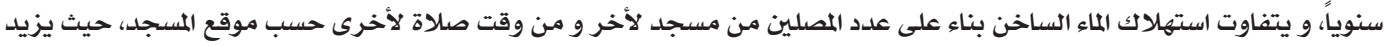

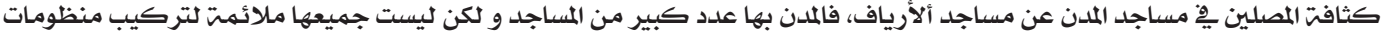

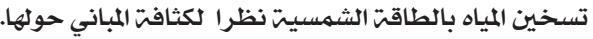

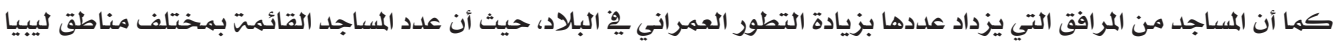

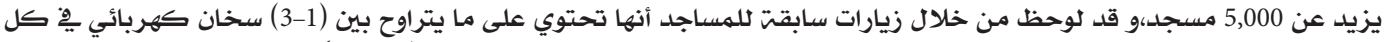

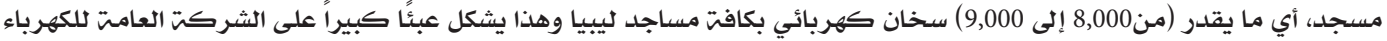

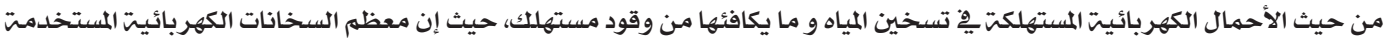

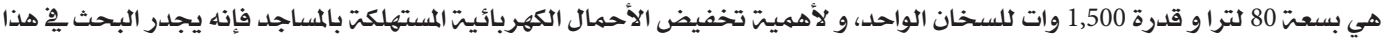

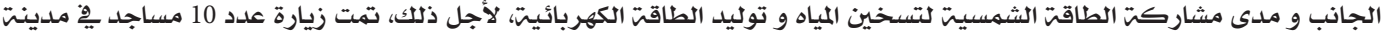

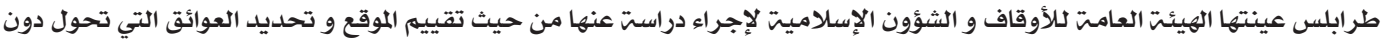

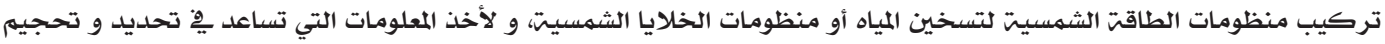
المنظومات الكلازمتي.

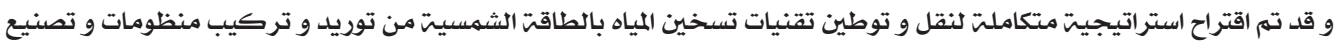

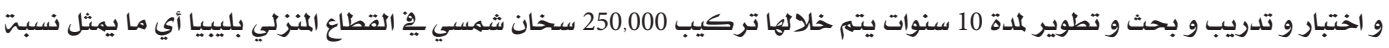

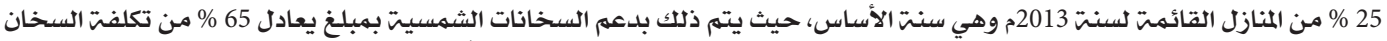

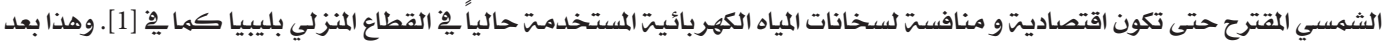

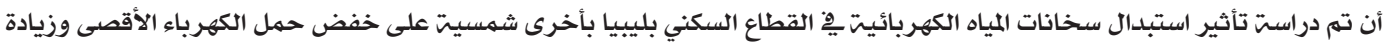

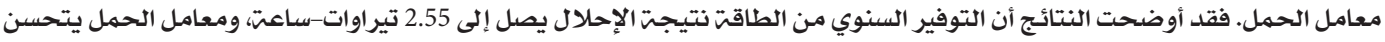

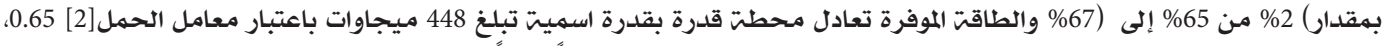

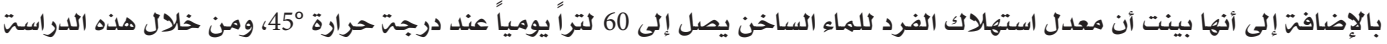

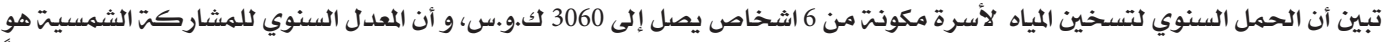

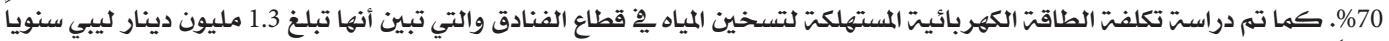

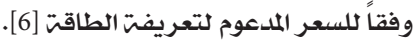

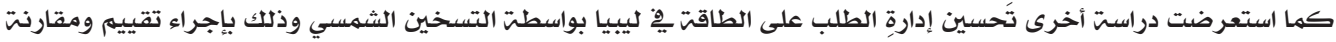

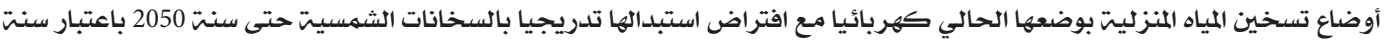




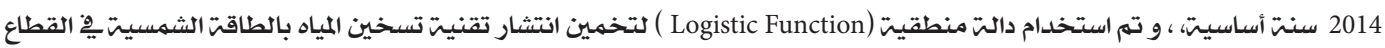

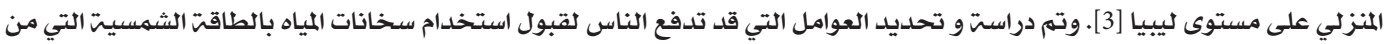

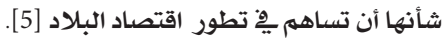

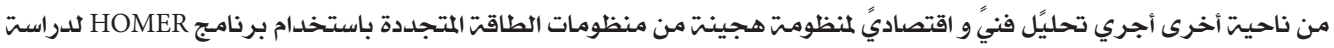

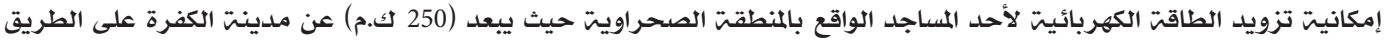

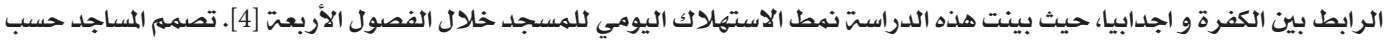

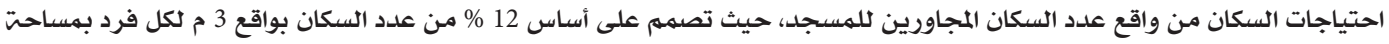

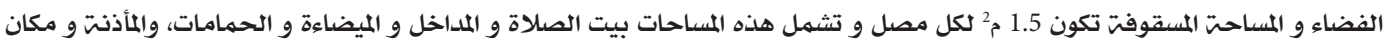

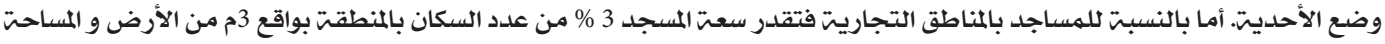

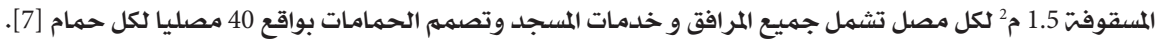

\section{2 ـ دوافع تركيب منظومات تسخين المياه بالطاقة الشمسية في المساجد}

بإمكان السخانات الشمسيتة توفير ما يزيد عن 70 \% من الطلب على الماء الساخن.

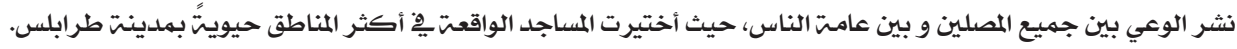

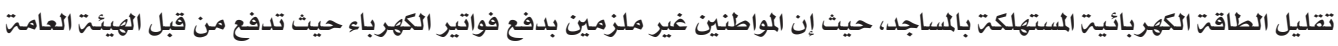

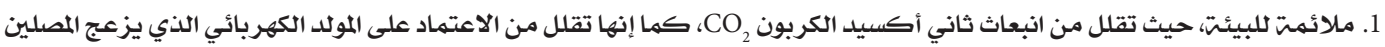

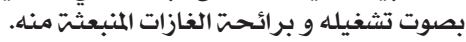

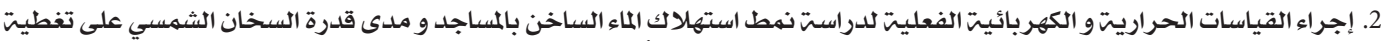

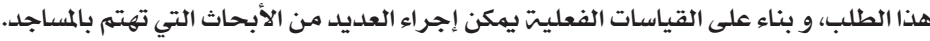

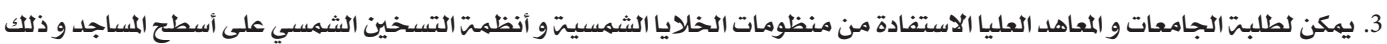

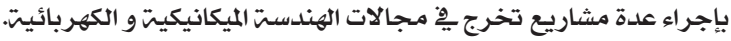

\section{3. متطلبات تركيب منظومات تسخين المياه بالطاقة الشمسية}

1.3. الحوافز الماليت

هذه الحوافز تؤثر مباشرة على فترة الاسترداد والعائد على الاستثمار و تشجيع المواطنين على تركيب منظومات تسخين المياه

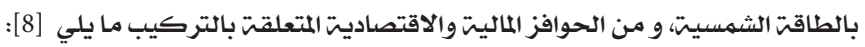

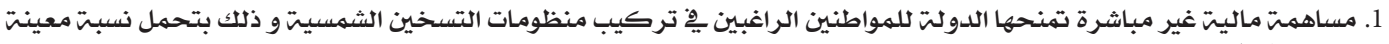
من التكلفت.

2. تخفيض أو الإعفاء من الضر ائب الجمركيت على موردي منظومات التسخين الشمسي. 3. منح قروض بلدون فوائد تسلد عن طريق المصارف يِ حال تحميل التكلفت على المواطن. 2.3. الحوافز غير الماليت

\section{يشمل هذا النوع من الحوافز [8] :}

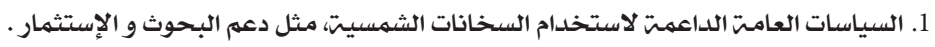

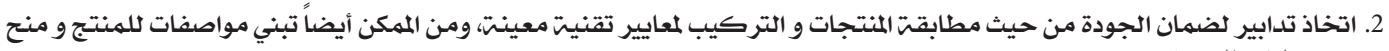
شهادات للمبركبين.

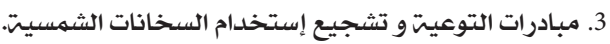
4. الحوافز الأكثر أهميت هي إصدار الأحكام القانونيت التي تجعل تركيب منظومات تسخات تسخين المياه بالطاقت الشمسيت إلزامياً ِِِ المباني الجنديدة. 5. إقامت الدورات التدريبيت لفنيي التركيب.

\section{4. منظومات تسخين الياه بالطاقة الشمسية المقتزح دراستها}

هِ هذه الدراست تم الأخذ بعين الاعتبار نوعين من منظومات تسخين المياه بالطاقت الشمسيت المقترح تركيبها على أسطح المساجد و

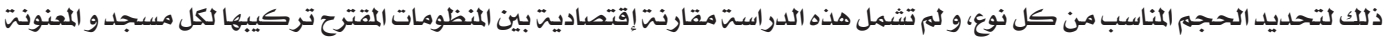

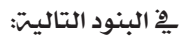


1.4. استخدام منظومات الطاقتمالشمسيتّذات الدوران الطبيعي (Thermosiphone)

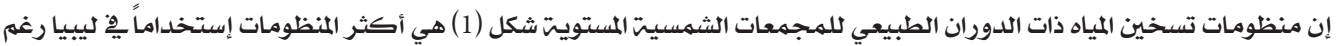

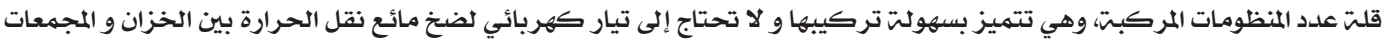

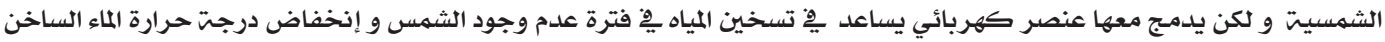

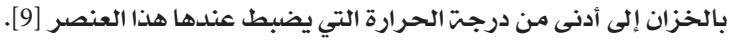

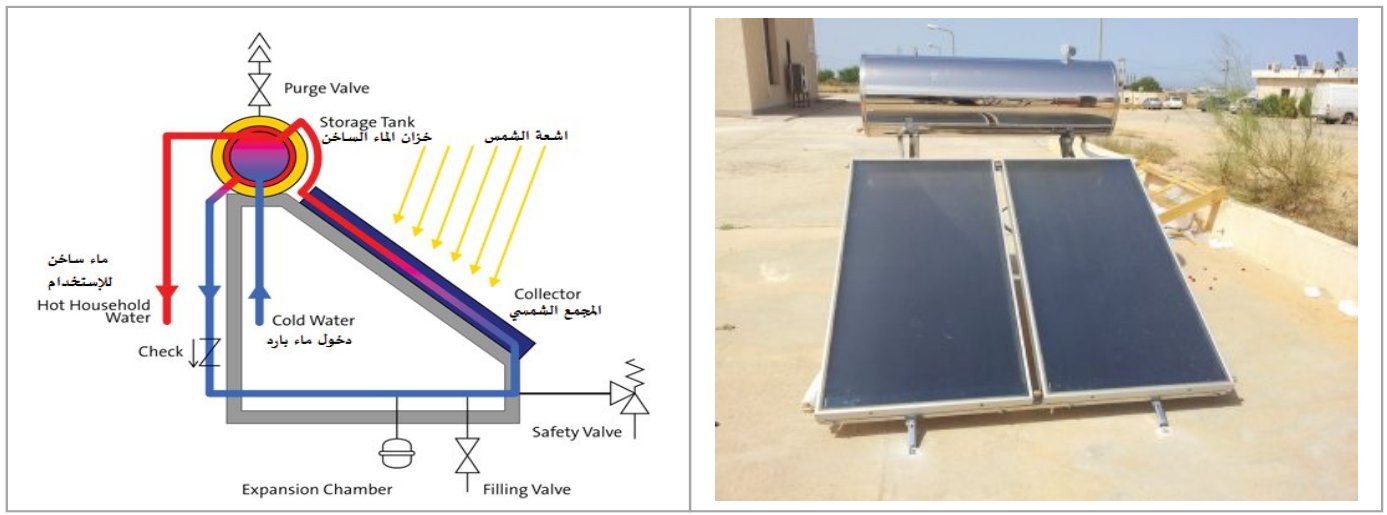

شكل (1). منظومت الدوران الطبيعي لتستخين المياه بالطاقت الشمسيت [9].

2.4. استخدام منظومات الطاقت الشمسيت لتستخين المياه ذات الدوران القسري (Forced Circulation)

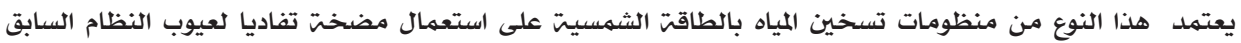

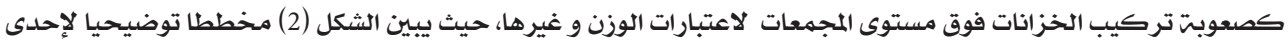

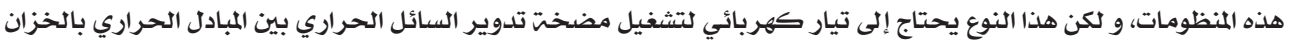

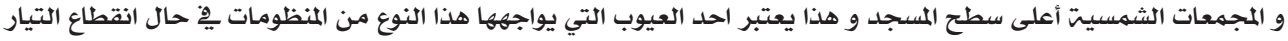

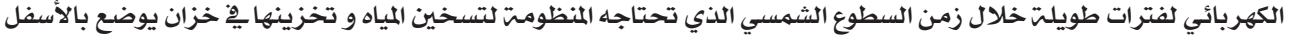

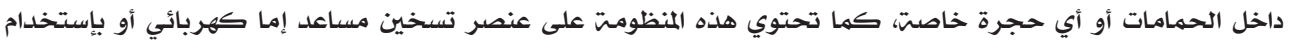

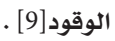

و يٌْ هذه الدراست تم تحليل حمل تسخين المياه باستخدام هذا النوع من المنظومات لمسجد القدس و ذلك بهدف مقارنتها كحل بلديل للمنظومات السابقت.

\section{5. دراسة إمكانية تركيب منظومات تسخيز المياه بالطاقة الشمسية على أسطح المساجد}

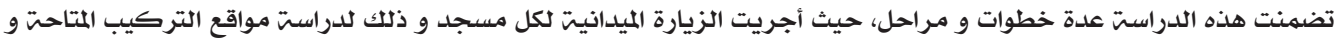

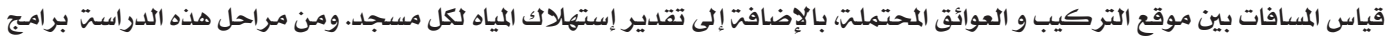

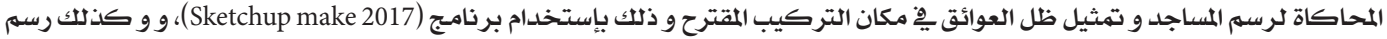

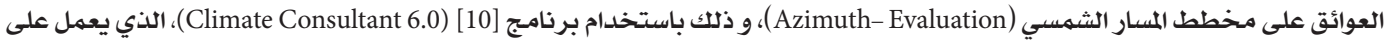

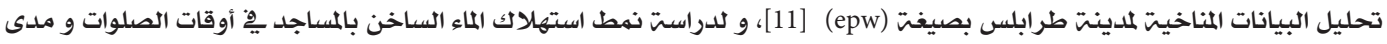

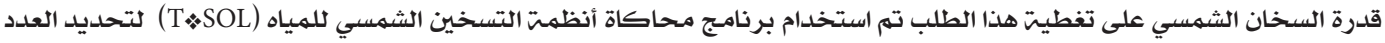
الكايِّ من المنظومات لكل مسجد. 


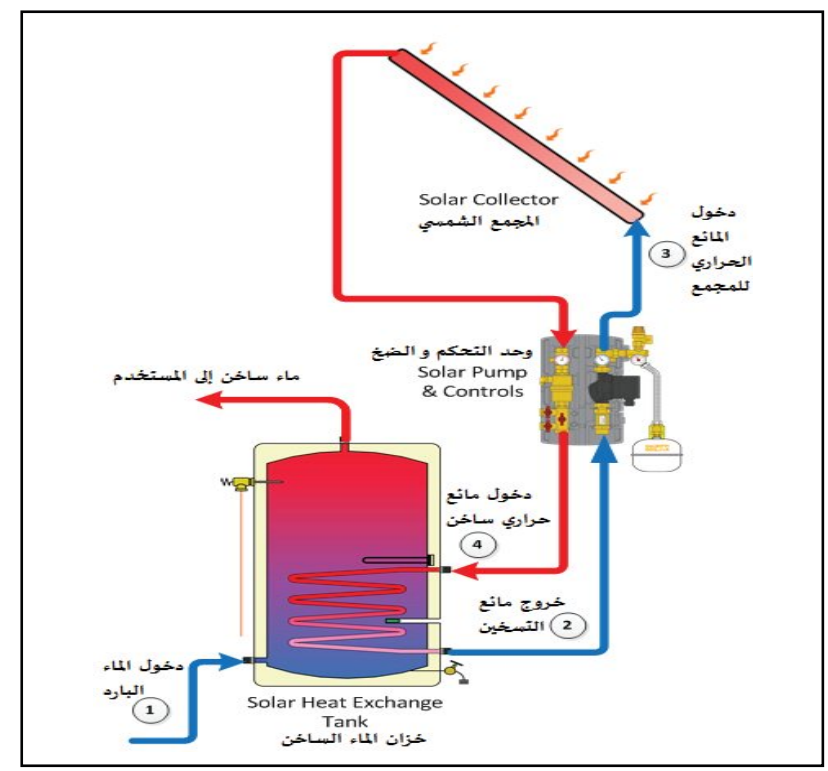

شكل (2). المنظومت الشمسيت ذات الدوران القسري لتسخين المياه [9].

1.5. الزيارة الميدانيتت لجمع بيانات الإستهلالك بالمساجد

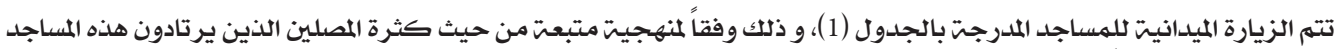

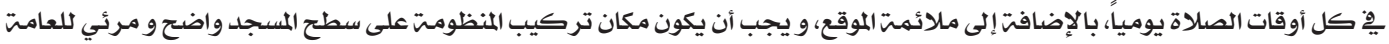

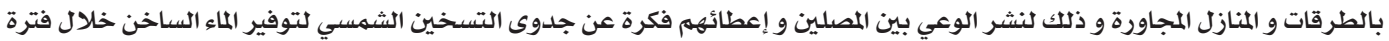

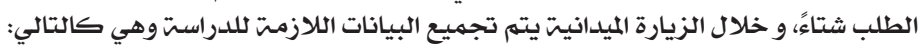

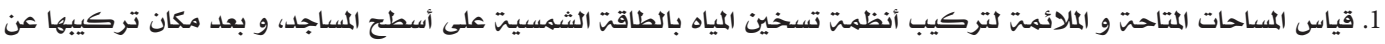
المواضئ.

$$
\text { 2. دراست مدى وصول الإشعاع الشمسي لموقع التركيب. }
$$

3. تحديد معوقات التركيب (الظل و عدم كفايت الموقع) و النظر بٍِ إمكانيت تفادي هذه المعوقات.

4. تقدير عدد المصلين الذين يرتادون المساجد ٌِِ كل أوقات الصلاة يومياً وذلك وفقاً لمعلومات القيمين و إمامت الأوقات بالمساجد.

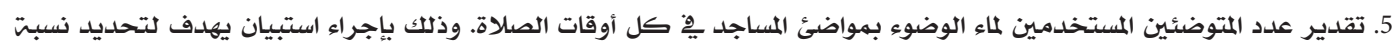

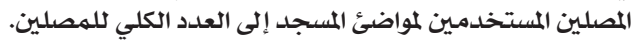

6. تقدير كميت الماء الساخن المستهلكت يومياً لتحديد عدد المنظومات المطلوبت لكل مسجدي المسلد.

$$
\text { 2.5. تقييم مواقح التركيب. }
$$

بناء على الزيارة الميدانيت للمساجد لدراست إمكانيت تركيب سخانات شمسيت على أسطح المساجد فقد تم تقييهم موقع التركيب من

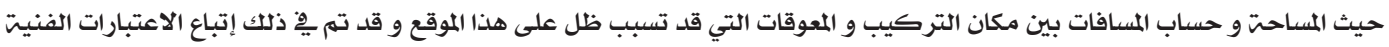
المتبعت التاليت:-

1. تم تقييم مواقع المساجد بناء على حسابات زوايا الظل و زوايا الشمس ليوم 12/21. 2. تم تمثيل ظل الحوائل المتمثلت يْ المباني المجاورة و الأشجار باستخدام برنامـج (SketchUp Make 2017)، حيث أخذ مسقط الظل عند

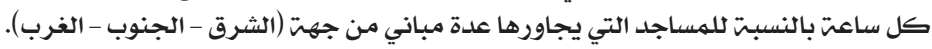
3. تم رسهم العوائق كالمباني و الأثجار المجاورة للمساجد على خريطت المسار الثمسي (Evaluation -Azimuth)، باستخدام البرنامـج 
المجاني إستشاري المناخ (0.6 Consultant Climate) فهو برنامج كمبيوتر مجاني وسهل الاستخدام للمهندسين المعماريين والبنائين

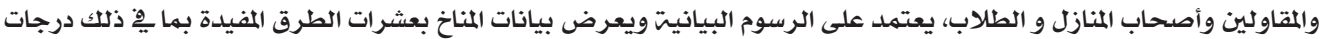

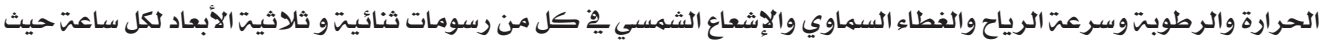

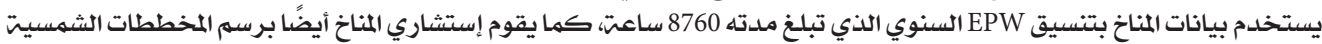

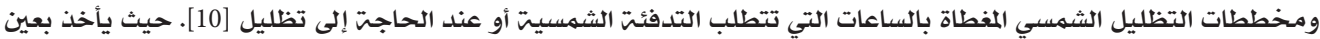

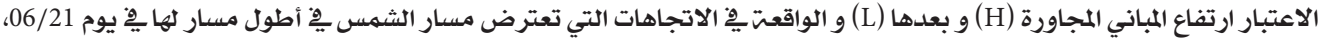

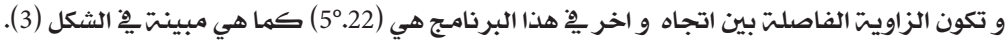

جدول (1). قائمت المساجد المقتوحت من هيئت الأوقاف و الشؤون الإسلاميت

\begin{tabular}{|c|c|c|c|c|}
\hline \multicolumn{2}{|c|}{ إحداثيات الموقع } & المنطقت & أسم المسجد & $ت$ \\
\hline “ $19.17^{\prime} 13^{\circ} 12$ & “49.61'3253 & زاويتّ الدهماني & مسجد القوزقو & 1 \\
\hline “ $51.05^{\prime} 13^{\circ} 11$ & “ $21.28^{\prime} 32^{\circ} 53$ & الظهرة & مسجد ابو ظهير & 2 \\
\hline “ $54.74^{\prime} 13^{\circ} 12$ & “ $0.81^{\prime} 32^{\circ} 53$ & الهاني & مسجد الزويكي & 3 \\
\hline “ $8.00^{\prime} 13^{\circ} 11$ & “ $59.83^{\prime} 32^{\circ} 52$ & شارع الزاويت & مسجد الماجديت & 4 \\
\hline “46.55'1311 & “ $56.51^{\prime} 32^{\circ} 52$ & بن عاشور & مسجد بن ناجي & 5 \\
\hline “ $24.63^{\prime} 13^{\circ} 11$ & “ $33.34^{\prime} 32^{\circ} 53$ & الظهرة & مسجد بالإمام & 6 \\
\hline “ $40.70^{\prime} 13^{\circ} 12$ & “ $27.94^{\prime} 32^{\circ} 52$ & شارع الظل & مسجد العنقودي & 7 \\
\hline “9.38'13º 11 & “ $19.58^{\prime} 32^{\circ} 53$ & شارع 24 ديسمبر & مسجد المغاربت & 8 \\
\hline “ $16.75^{\prime} 13^{\circ} 11$ & “ $56.86^{\prime} 32^{\circ} 52$ & شارع الجمهوريت & مسجد مولاي محمد & 9 \\
\hline \multirow[t]{8}{*}{ “ $43.88^{\prime} 13^{\circ} 10$} & “ $49.13^{\prime} 32^{\circ} 52$ & جزيرة القدس & مسجد القدس & 10 \\
\hline & \multicolumn{2}{|c|}{ تفسير الرموز } & 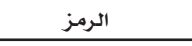 & \\
\hline & \multicolumn{2}{|c|}{ شمال شرق - الشرقي } & ENE & \\
\hline & \multicolumn{2}{|c|}{ الشرق } & $\mathrm{E}$ & \\
\hline & \multicolumn{2}{|c|}{ جنوب شرق الشرقي } & ESE & \\
\hline & \multicolumn{2}{|c|}{ جنوب شرق } & SE & \\
\hline & \multicolumn{2}{|c|}{ جنوب شرق الجنوبي } & SSE & \\
\hline & \multicolumn{2}{|c|}{ الجنوب } & S & \\
\hline w & \multicolumn{2}{|c|}{ جنوب غرب الجنوبي } & SSW & \\
\hline & \multicolumn{2}{|c|}{ جنوب غرب } & SW & \\
\hline WNW & \multicolumn{2}{|c|}{ جنوب غرب الغربي } & WSW & \\
\hline & \multicolumn{2}{|c|}{ الغرب } & $\mathrm{W}$ & \\
\hline & \multicolumn{2}{|c|}{ شمال غرب الغربي } & WNW & \\
\hline
\end{tabular}

شكل (3). الإتجاهات التي تمثل زاويت السمت (Azimuth) للمباني المجاورة لمكان التركيب

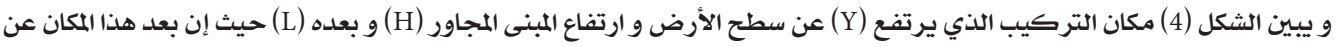

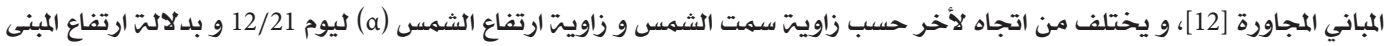

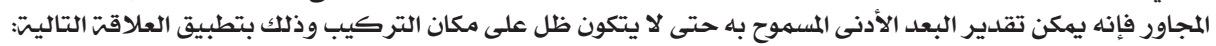

$$
L>\frac{(H-Y)}{\tan \alpha}
$$

و من العلاقت (1) و بتطبيق زاويت ارتفاع الشمس (a) ليوم 12/21 (ديسمبر) المبينت بشكل (5) فإنه يمكن تقدير أقل بعد للمباني

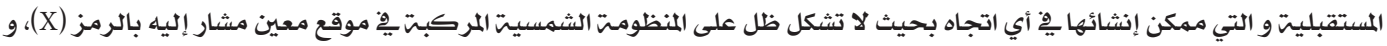

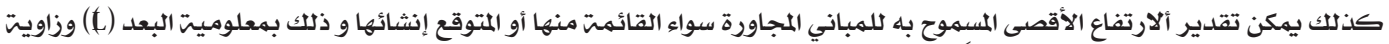

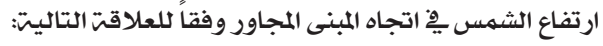


$H<(Y+L \tan \alpha)$

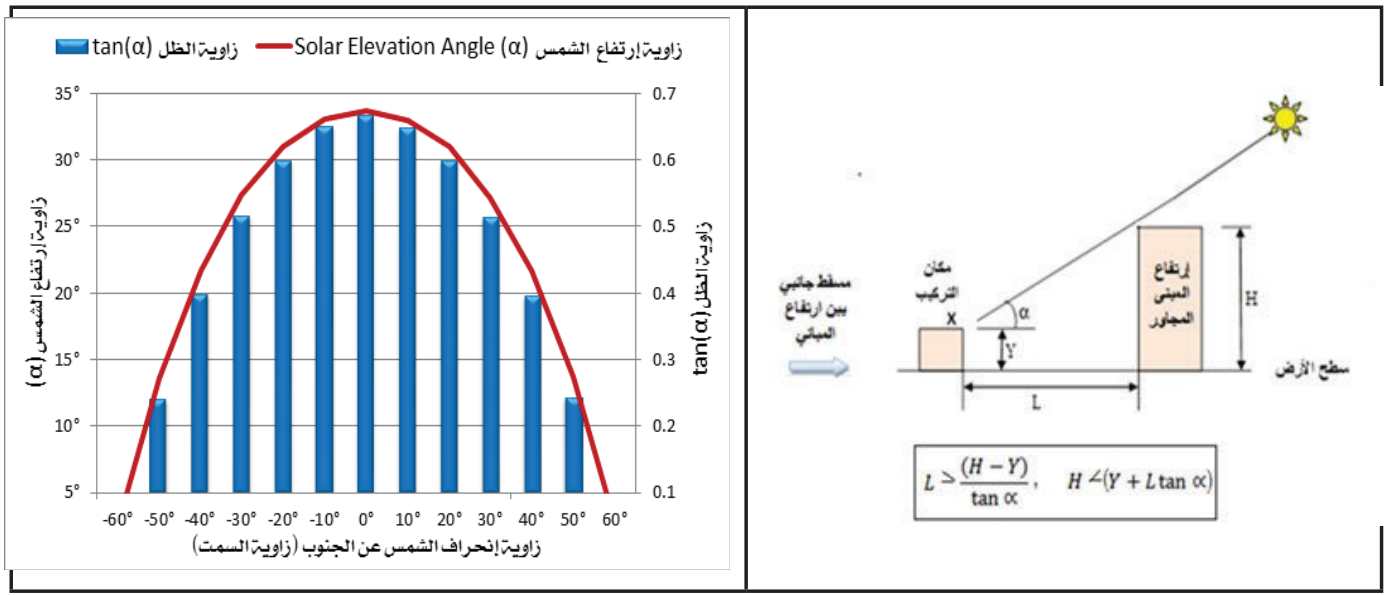

شكل (5) تمثيل زاويتتا ظل ارتفاع الشمس بدلالتمزاويت السمت

شكل (4) مخطط يبين ارتفاع و بعد للمبنى المجاور لموقع التركيب

3.5. تصنيف المواقع المقترحتّللتركيب. تصنف المساجد حسب إمكانيت تركيب منظومات تسخين المياه الشمسيت من حيث مساحت التركيب و تكون ظلال المباني المجاورة

على موقع التركيب إلى التصنيف التالي:-

1.3.5 مساجد متاحت للتركيب

هذا الصنف من المساجد يشمل كل من مسجد الزويكي، مسجد أبوظهير، مسجد المغاربت و مسجد القدس، حيث يحتوي كل منها

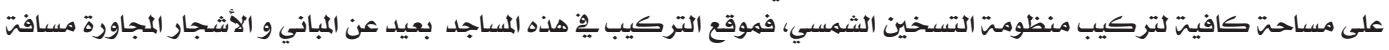

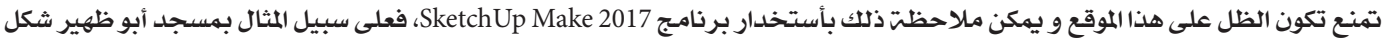

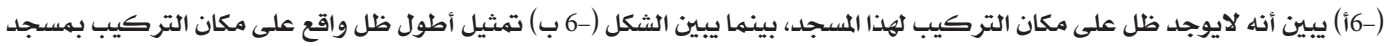

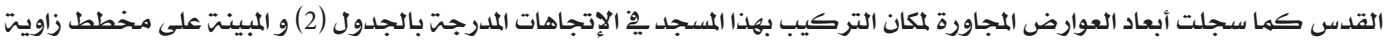

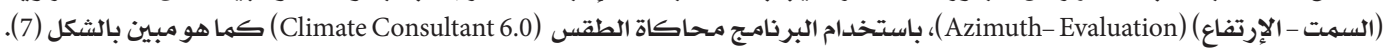

2.3.5. مساجد غير متاحمت للتركيب:

و يشمل هذا الصنف كل من مسجد القوزقو، مسجد بالإمام و مسجد مولاي محمدد و مسجد الماجديت حيث توجد بها مساحت

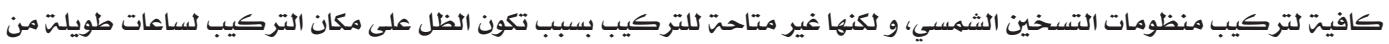

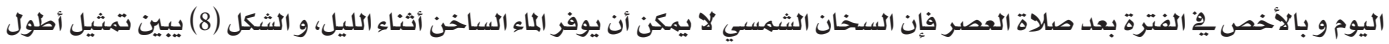

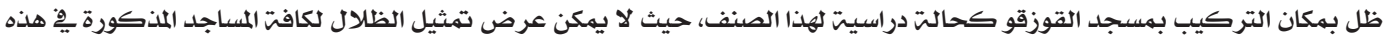

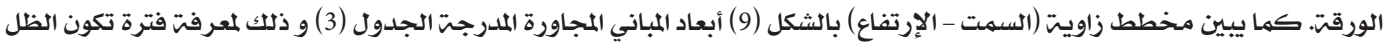

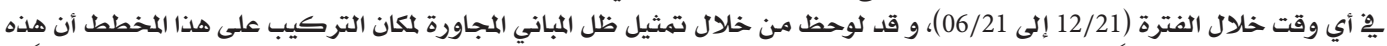

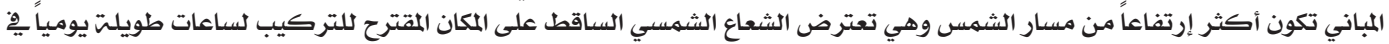
الشهور التي يحتاج فيها إلى إستخدام المياه الساخنتش و الممتدة من شهر ديسمبر إنى إلى شهر مارس.حسب هذا المخطط. 

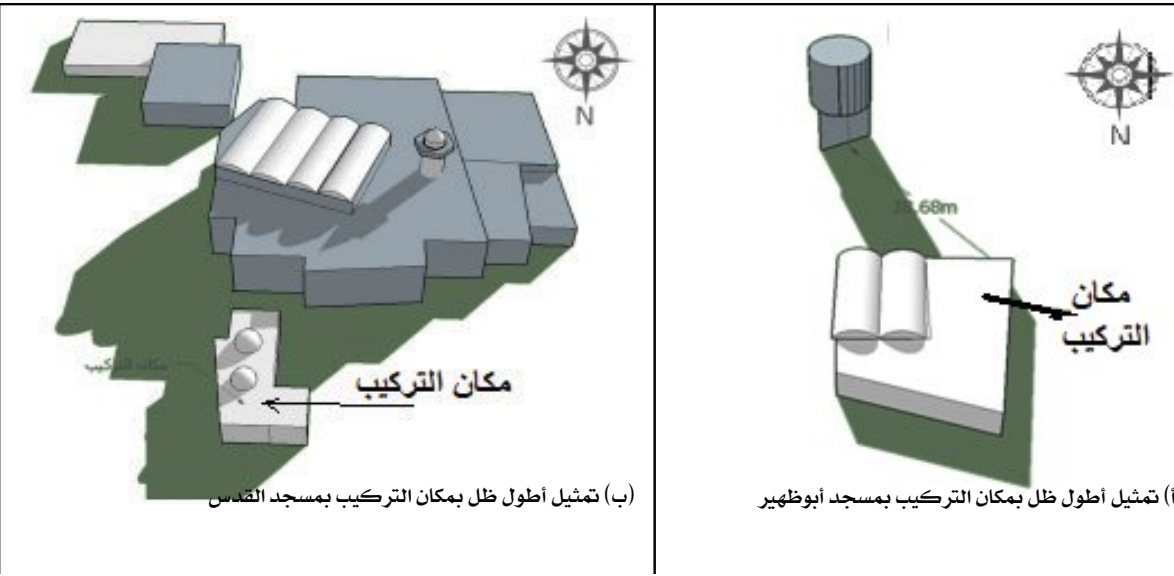

شكل (6) تمثيل الظلال بمكان التركيب بالمساجد متاحت التركيب

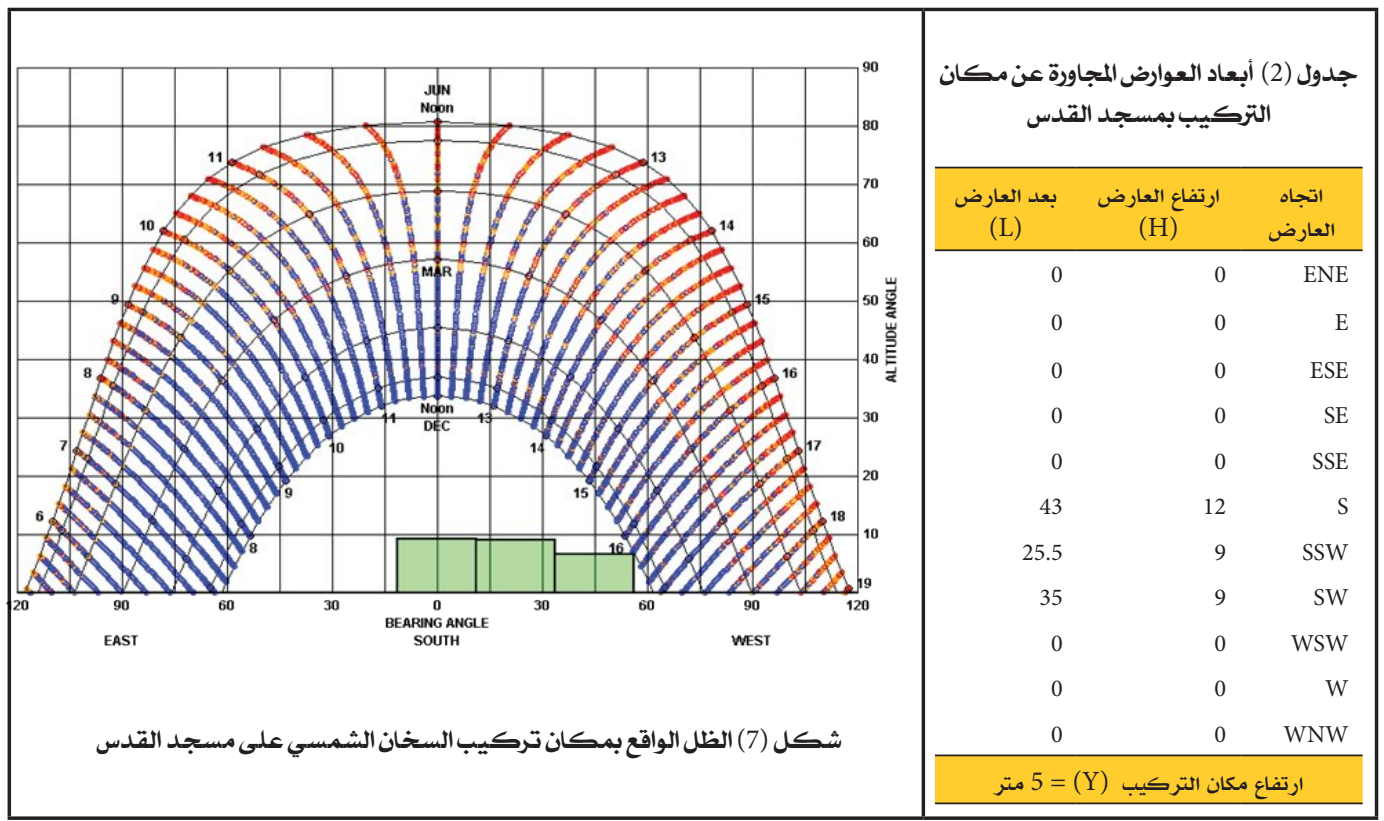

3.3.5 مساجد تكفي لتركيب سخان شمسي واحد :

و هناك بعض المساجد لا تملك المساحت الكافيت لتركيب العدد الكايِّ من منظومات التسخين الشمسي و ذلك لكون سطح المسجد

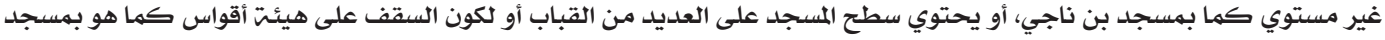

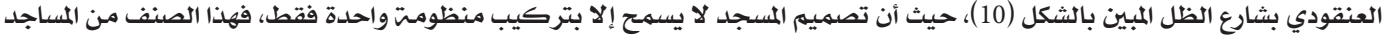

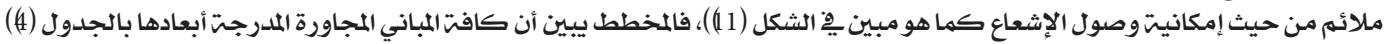

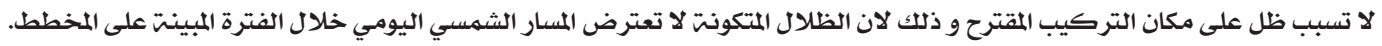

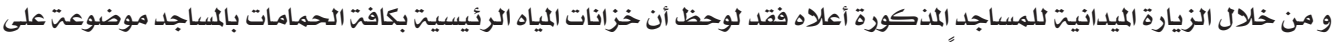

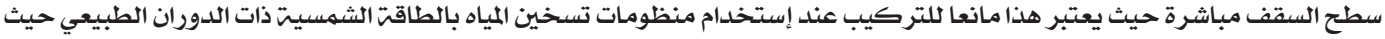

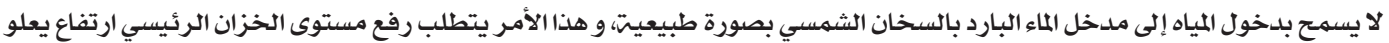

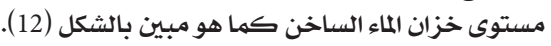



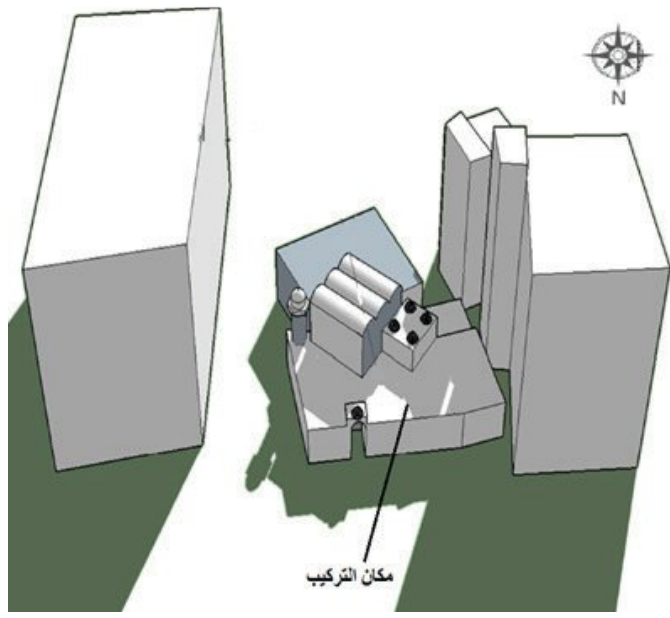

شكل (8). تمثيل أطول ظل بمكان التركيب بمسجد القوزقو

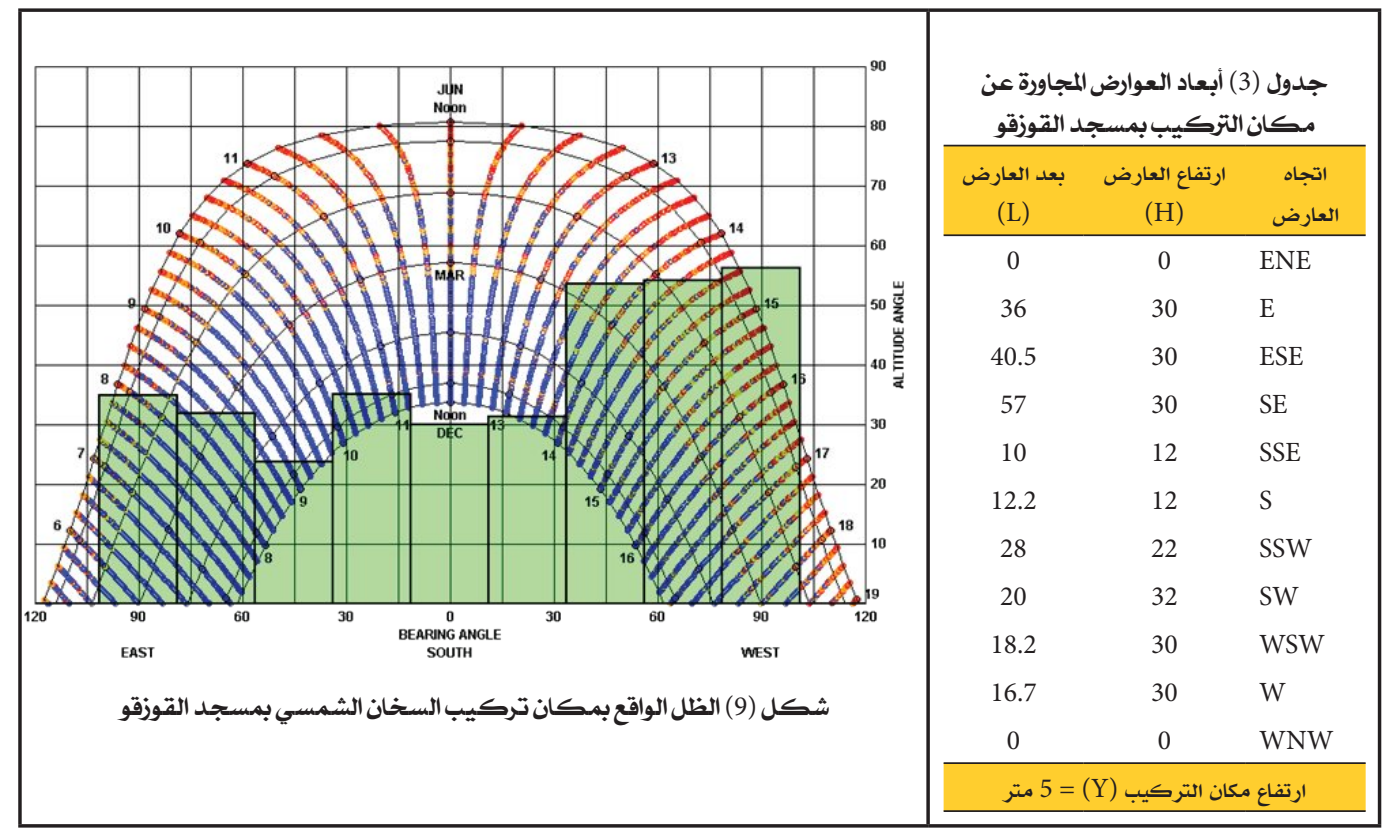

6. تقدير استهالكك الياه الساخنة للوضوي بالمساجد.

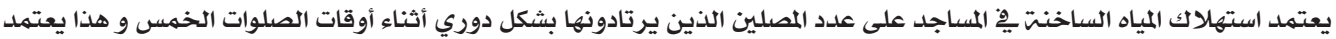

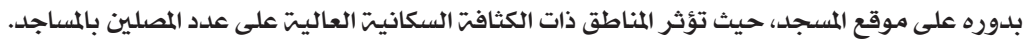
1.6. تحديد كميت الماء الساخن

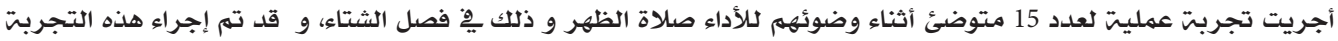

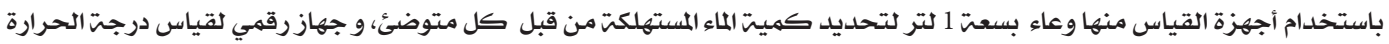

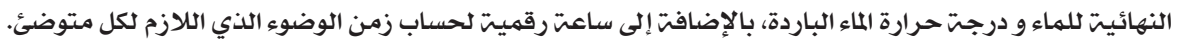




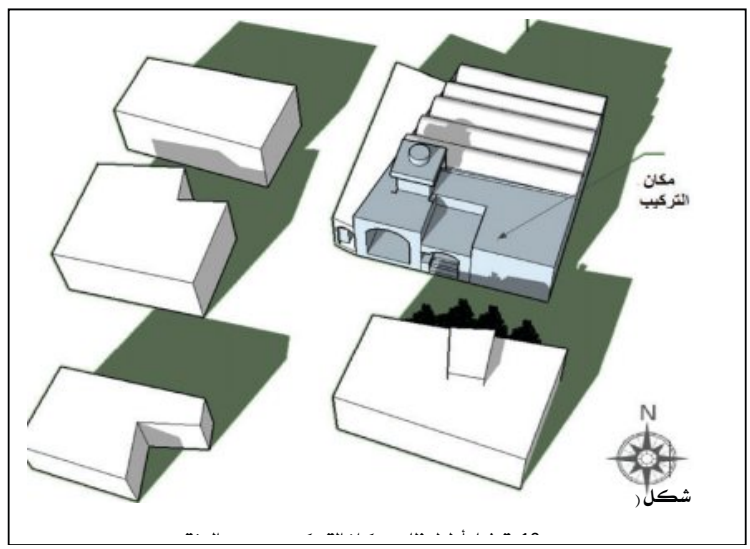

شكل (10) تمثيل أطول ظل بمكان التركيب بمسجد العنقودي

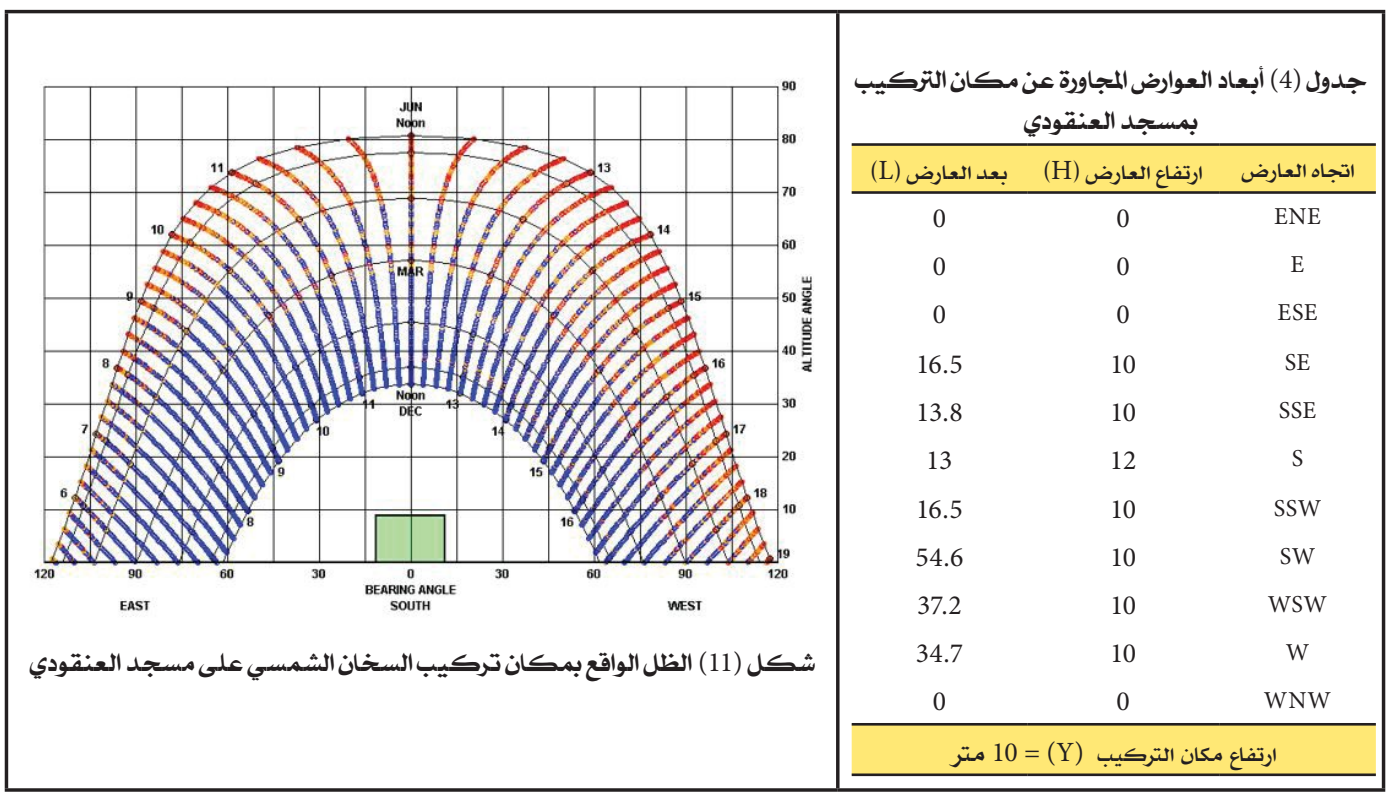

1.1.6. أهداف القياسات العمليت لماء الوضوء

إن إجراء بعض القياسـات كلرجت حرارة الماءو و كهيتها للمتوضئين يهدف إلى ما يلي:

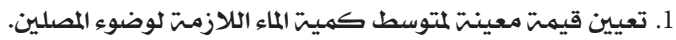
2. درجت الحرارة المعدلت (مـخلوط الماء الساخن و البارد) الخارجت من الحنفيتّ و هي تختلف من متوضئ لأخر و ذلك على حسب درجت الراحت لكل منهمه. 


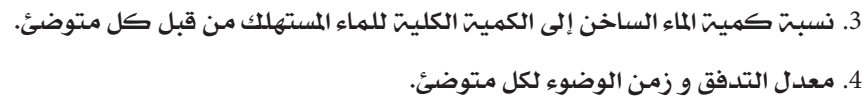

5. تحديد العدد الكايِّ لكل مسجد من منظومات التسخين الشمسي ذات السعت 300 لتر.

\subsection{6 نتائج القياسات العمليت}

و يبين الجدول (5) البيانات التي سجلت أثناء وضوء عدد 15 مصلي، و أخذت النتائج كالتالي:-

1. متتوسط لكميت استهلاك الماء التي يحتاجها المتوضئ من خليط الماء الساخن مـع الماء البارد 3.43 لتر.

2. متتوسط درجت حرارة خليط الماء التي يرغبها الإنسان 40.12 درجت مئويت.

3. متوسط الزمن المستغرق للوضوء هو 61.1 ثانيت.

جدول (5) البيانات المقاست لمياه الوضوء لعدد 15 مصلي

\begin{tabular}{|c|c|c|c|c|c|c|}
\hline درجت حرارة الجو & درجت حرارة الماء & معدل التدفق لترا & لدرجت & استهلاك المماء بالتر & زمن & ت \\
\hline 18.2 & 19 & 0.0625 & 46 & 3 & 48 & 1 \\
\hline 18.2 & 19 & 0.0471 & 44 & 4 & 85 & 2 \\
\hline 18.2 & 19 & 0.0509 & 37 & 2.8 & 55 & 3 \\
\hline 18.2 & 19 & 0.0274 & 36 & 3.2 & 117 & 4 \\
\hline 18.2 & 19 & 0.0752 & 48 & 5 & 66.46 & 5 \\
\hline 18.2 & 19 & 0.0357 & 41 & 2 & 56 & 6 \\
\hline 18.2 & 19 & 0.0489 & 54 & 2.7 & 55.16 & 7 \\
\hline 18.2 & 19 & 0.0707 & 49 & 5.3 & 75 & 8 \\
\hline 18.2 & 19 & 0.0611 & 36 & 3.3 & 54 & 9 \\
\hline 18.2 & 19 & 0.0602 & 30 & 3 & 49.85 & 10 \\
\hline 18.2 & 19 & 0.0249 & 30 & 2.1 & 84.4 & 11 \\
\hline 18.5 & 19 & 0.0824 & 37.8 & 3.5 & 42.5 & 12 \\
\hline 18.5 & 19 & 0.0952 & 40 & 2.6 & 27.32 & 13 \\
\hline 18.5 & 19 & 0.0596 & 35.8 & 2.7 & 45.27 & 14 \\
\hline 18.5 & 19 & 0.1110 & 37.2 & 6.3 & 56.78 & 15 \\
\hline 18.28 & 19 & 0.0608 & 40.12 & 3.433 & 61.183 & المتوسط \\
\hline
\end{tabular}

و بناء على نتائج استبيان خاص بالمساجد ِِّ منطقت سوق الجمعت طرابلس تم إعداده ِِّ سنت 2012م، وشمل ما يقارب من ثلاثين

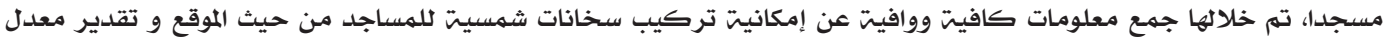

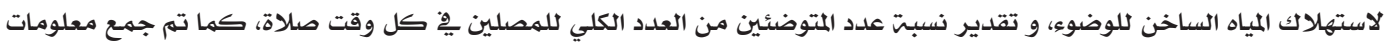

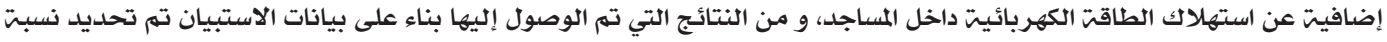

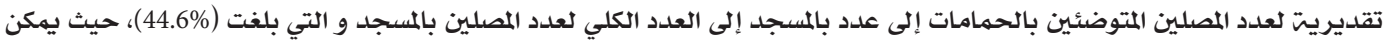

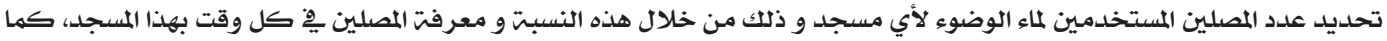

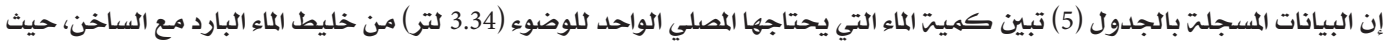

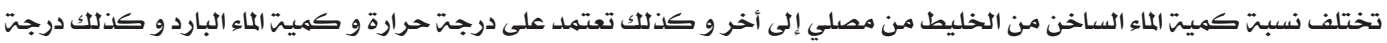

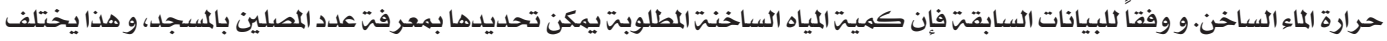
من مسجد لأخر، وقد تم اعتبار أن المتر الواحد من صفوف المصلين يكفي لعدد 2 مصلي، و ذلك عند تقدير عدد المصلين بالمسجد حيث يمليث يمكن

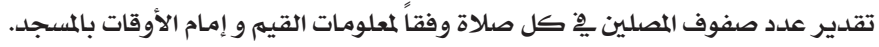




\section{7. تحليل أحمال تسخين الياه بمنظومات الطاقة الشمسية}

1.7. استخدام برنامج المحاكاة (T*SOL 5.5 Pro)

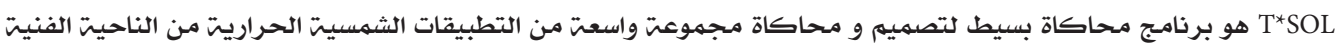

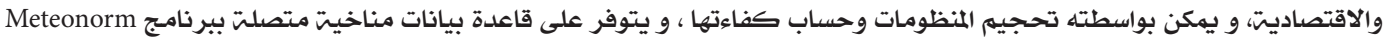

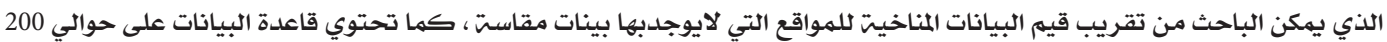

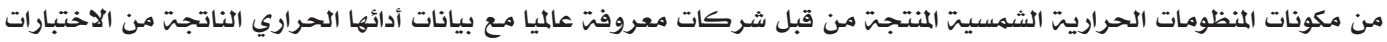

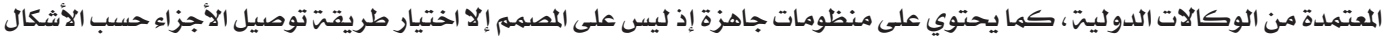

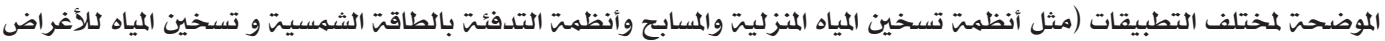

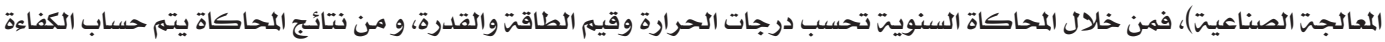

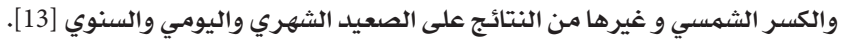

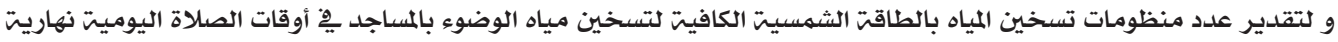

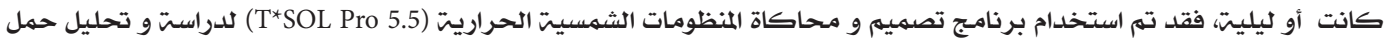

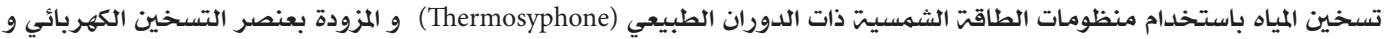

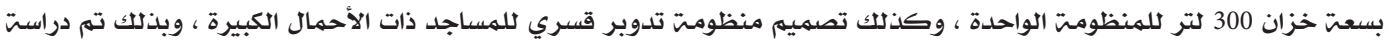

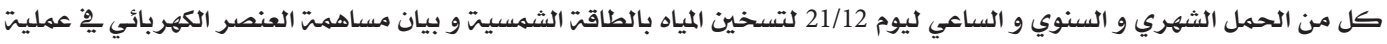

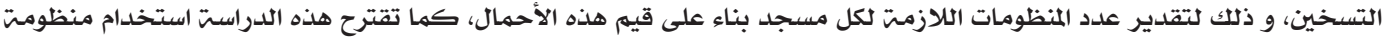

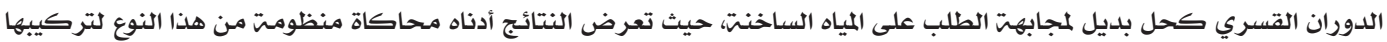

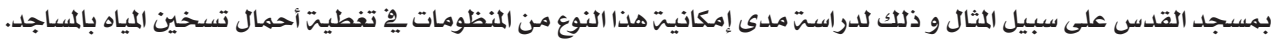

2.7. تحليل نتائج المحاكاة للمساجد متاحتّللتركيب

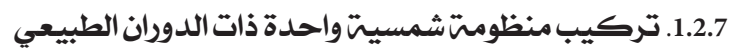

من خلال مخططات الحمل السنوي لتسخين المياه لمسجد القدس المبين بالشكل (13- أ) يلاحظ أن استخدام منظومت واحدة تسخين

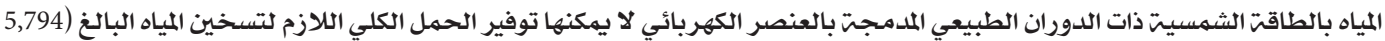

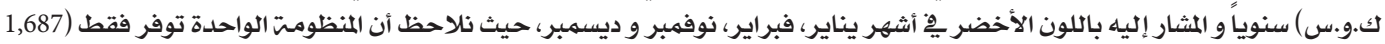

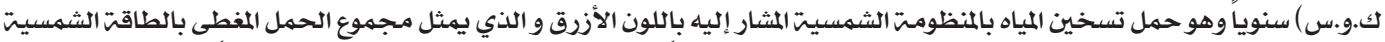

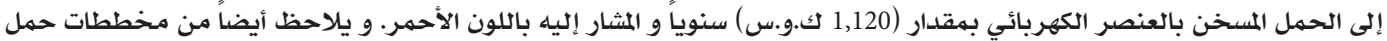

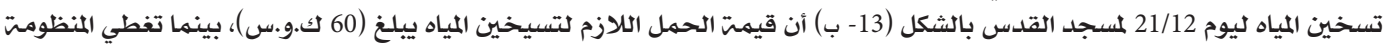

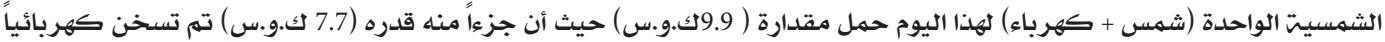

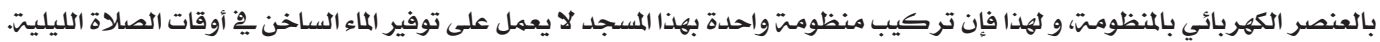

\subsection{7. تركيب العدد الكافي من المنظومت شمسيت ذات الدوران الطبيعي}

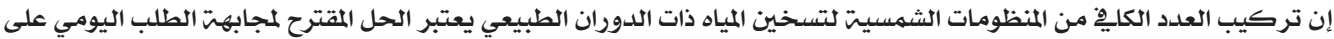

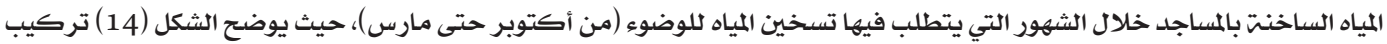

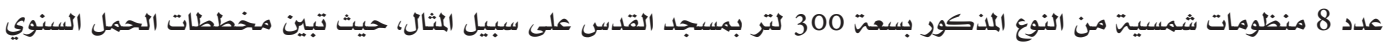

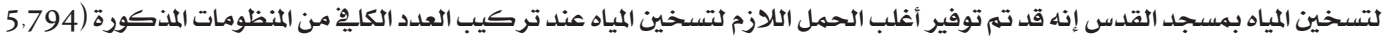

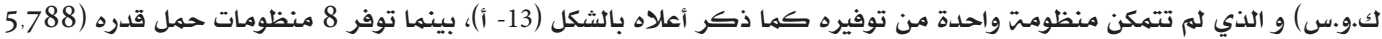

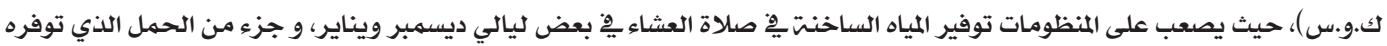

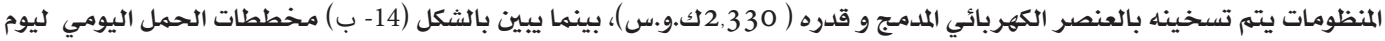

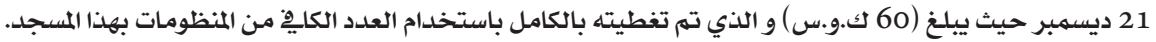




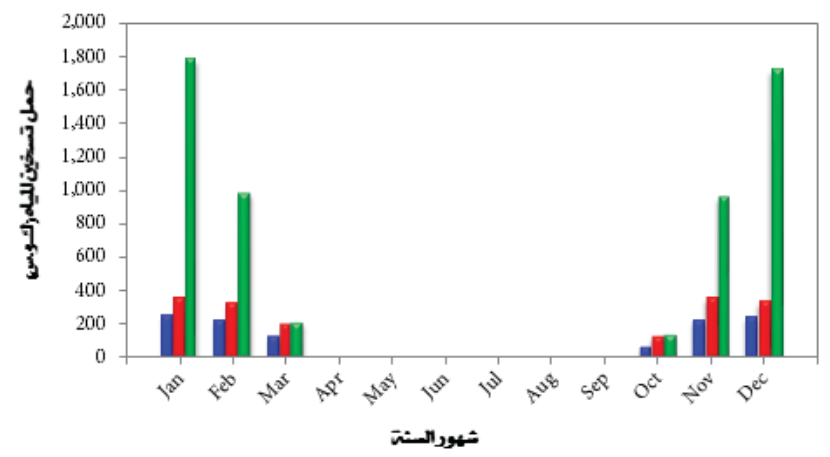

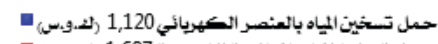

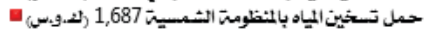

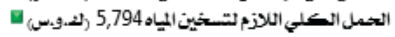

(أل الحمل السنوي لتسخين المياه بمسجد القدس

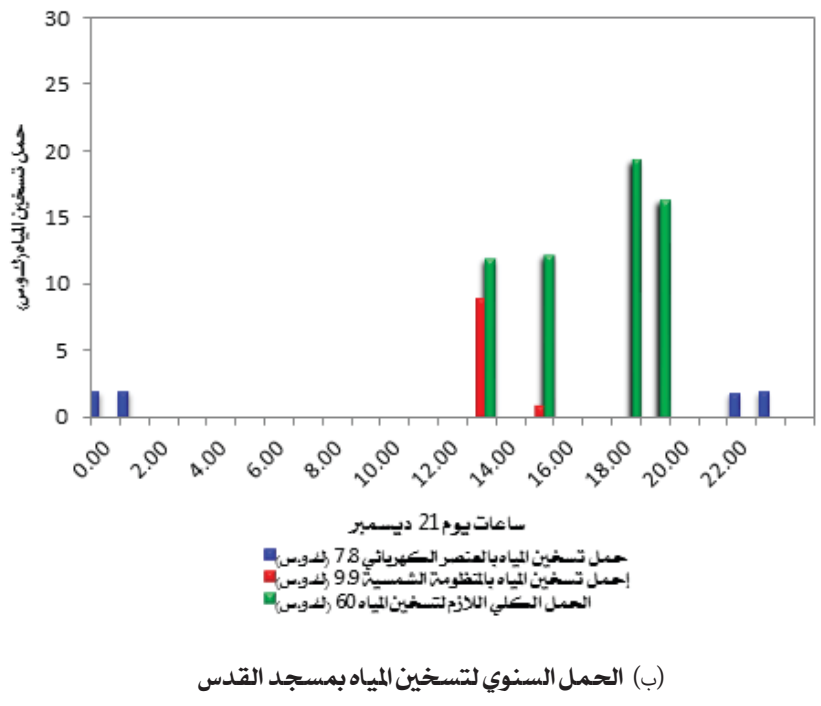

شكل (13) تركيب منظومت شمسيت واحدة ذات الدوران الطبيعي بمسجد القدس

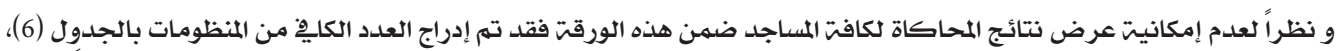

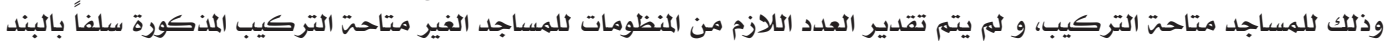

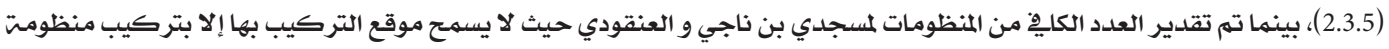

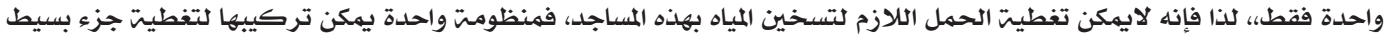

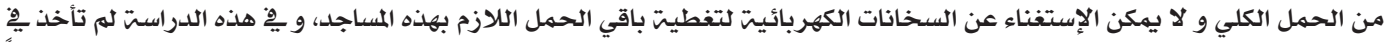

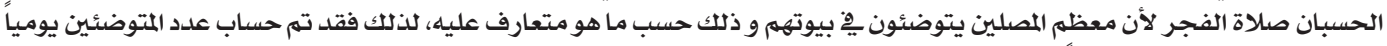
على أساس عدد 4 صلوات يومياً. 

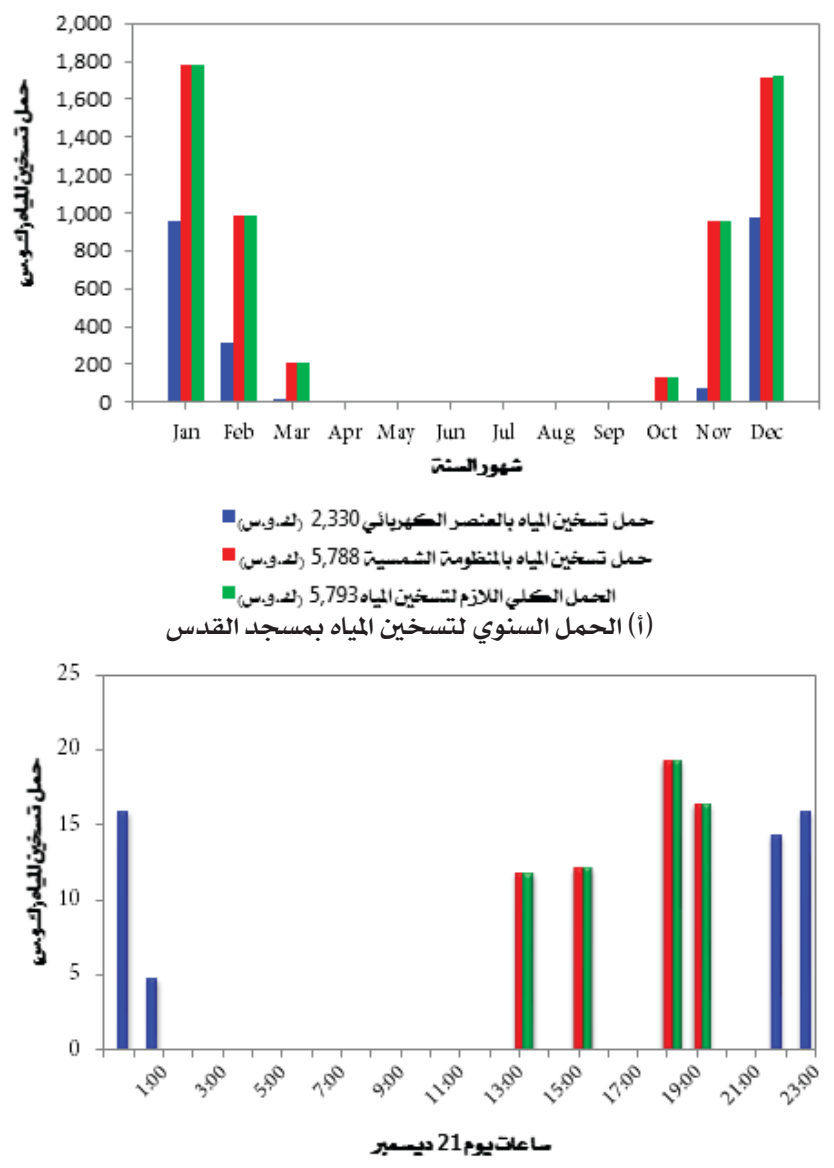

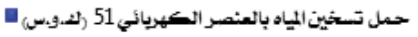

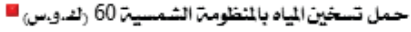

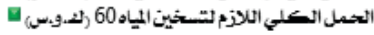

(ب) حمل تستخين المياه في يوم 21/12 بمستجد القدس

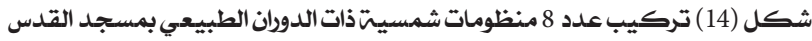

3.2.7. تركيب منظومتش الطاقتّ الشمسيتشّات الدوران القسري

إن الحل البديل لمجابهت الحمل الكلي الكلازم لتسخين المياه هو تركيب منظومت الطاقت الشمسيت ذات الدوران القسري بمساحت

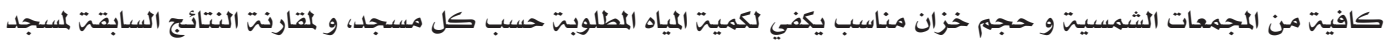

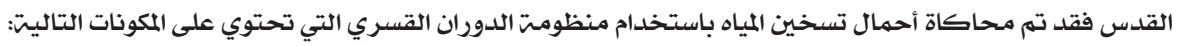
1. 10 أمتار مربعت من المجمعات الشمسيت من نوع (VIESSMANN، VITOSOL100)

2. خزان حراري 1500 لتر مزود بعنصر مساعد يعمل بالوقود. 3. تغطي أكثر من 60 \% من حمل الماء الساخن بالطاقت الشمسيت. 
جدول (6) بيانات الاستهلاك التقديري للماء الساخن بالمساجد و عدد منظومات التسخين الشمسي اللازمت

\begin{tabular}{|c|c|c|c|c|c|c|}
\hline ملاحظات & المنظومات & كماخيت الماء & عدد المتوضئينين & علدد المصلين & عدم الصدلاة المصلين & اسم المسجد \\
\hline يوجد ظل على موقع التركيب مِ معينت & ل لم تحسب & 1000 & 500 & 1192 & 298 & القوزقو \\
\hline الموقع ملائم للتركيب & 3 & 840 & 420 & 1000 & 240 & ابو ظهير \\
\hline الموقع ملائم للتركيب & 6 & 1410 & 705 & 1680 & 420 & الزويكي \\
\hline يوجد ظل على موقع التركيب مِّ & 7 & 1612 & 806 & 1920 & 480 & الماجديت \\
\hline مساحت التركيب تكفي لسخان & 3 & 740 & 370 & 880 & 220 & 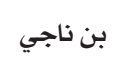 \\
\hline يوجد ظل على موقع التركيب ـِ & لم تحسب & 88 & 44 & 104 & 26 & 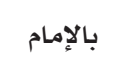 \\
\hline مساحت التركيب تكفي لسخان & 7 & 1344 & 672 & 1600 & 400 & العنقودي \\
\hline الموقع ملائم للتركيب & 4 & 1008 & 504 & 1200 & 300 & المغاربت \\
\hline 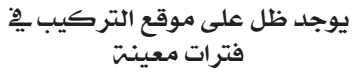 & لم تحسب & 1612 & 806 & 1920 & 480 & 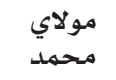 \\
\hline الموقع ملائم للتركيب & 7 & 1344 & 672 & 1600 & 400 & القدس \\
\hline
\end{tabular}

و تبين المخططات بالشكل (-16 أبب) أحمال تسخين المياه باستخدام منظوهت شمسيت ذات الدورات القسري و المقترح تركيبها بهسجد

القدس، حيث تم باستخدام برنامج لمحاكاة تصميم المنظومت بالحجم المناسب لتغطيت الحمل الشهري اللازم لتسخين المياه 5,793 ك.و.س) والذي سبق تبيينه بالشكل (-14)، و كذلك الحمل اللازم مٌِ يوم 21/12 الذي تم تبيينه سابقا بالشكل(-14) و مقداره (60 ك.و.س) حيث لهم تتمكن منظومت شمسيت واحدة ذات الدوران الطبيعي بسعت 300 لتير من تغطيت هذا الحمل، بينما توضح الشكلين (-16أ) و (-16-) الحمل الثهري و الحمل حمل يوم 21/12 على التوالي،و توضح المخططات إمكانيت المنظومت الشمسيت ذات الدوران القسري على توفير الحمل اللازم لتسخين المياه بالمسجد، حيث يمكن ملاحظت أن قيمت حمل تسخين المياه بالمنظومت الشمسيت المثار إليه باللون الأزرق مساوي لقيمت الحمل الكلي اللازم لتسخين المياه الذي قدره بالحمل الشهري (5,793 ك.و.س) و بحمل يوم 21/12 (60 ك.و.س)، علماً بأن

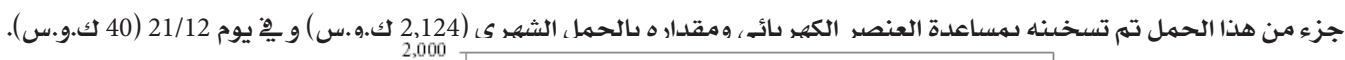

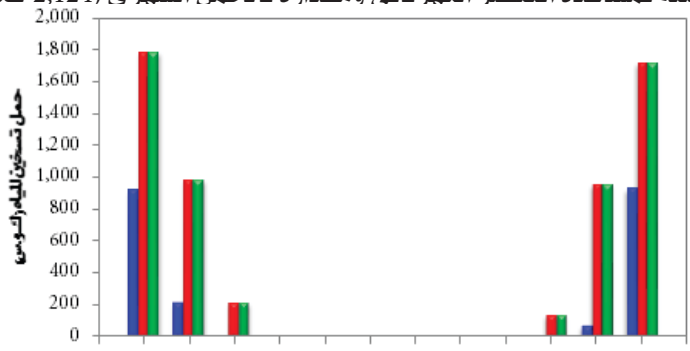

Jan Feb Mar Apr May Jun Jul Aug Sep Oct Nov Dec

$$
\text { شهورالسنت }
$$

حمل تسخين المياء بالعنصر الطهيريائي 2,124 (لض.و.س)

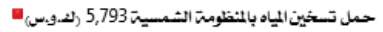

الحمل السلي اللازم لتسخين المياه 5,794 (لض.و.بري)

(أ) الحمل السنوي لتسخين المياه بمنظومت الحمل القسري 


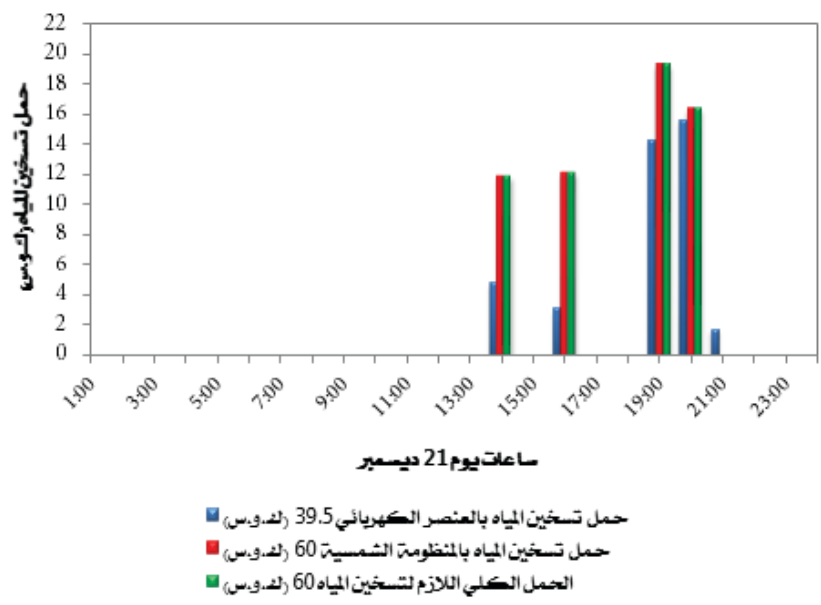

(ب) حمل تستخين المياه بمنظومت الحمل القسري في يوم 21 ديسمبر

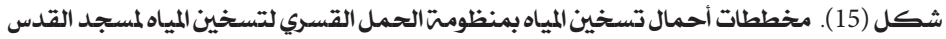

8. الخاتمة

تناولت هذه الدراست عدد 10 مساجد مِ مدينت طرابلس بمناطق تحتوي على مباني مرتفعت و عمارات سكنيت يمكن أن تمنع ظلالها الحصول الطاقت الشمسيت الحراريت الكافيت لتركيب المنظومات الشمسيت، أو تكون مساحات التركيب على سطحها غير مناسبت لهذه المنظومات، ومن خلال دراستت موقع التركيب للمساجد التي تم زيارتها تبين أن معظم المساجد غير ملائمته بسبب تكون الظل على أسطح

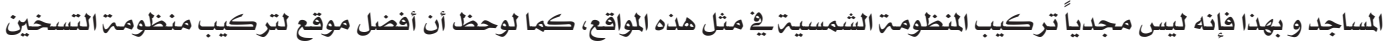
الشمسي يكون بالمساجد التي يكون موقع الحمامات بها جنوب المسجد، فعند بناء مساجد جلديدة يفضل أن يكون موقع الحمامات جنوب المسجد حتى لا يؤثر ظل المسجد على مكان تركيب السخان الشمسي، كما يتطلب بناء المساجد الجديدة توفير البنيت التحتيت التي تساعد

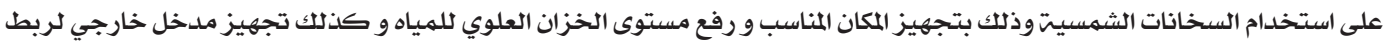
الماء الساخن بالحمامات ِِّ مرحلت إنشاء المسجد، حيث إن خزانات المياه العلويت بكافت المساجد التي تم زيارته موضوع على سطح سقفها

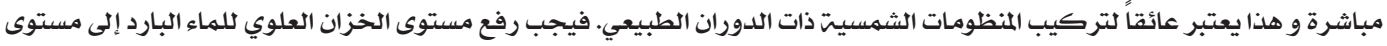

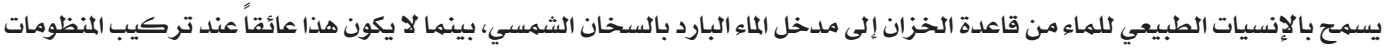
ذات الدوران القسري. ومن خلال الزيارة الميدانيت للمساجد لوحظ أنها واقعت ِِّ مناطق ذات كثافت سكانيت عاليت، فضلاً عن أنها مناطق تجاريت و ذات

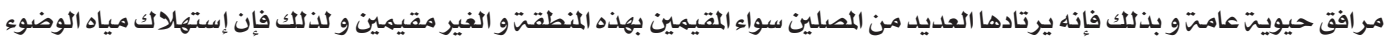

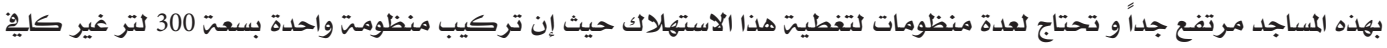

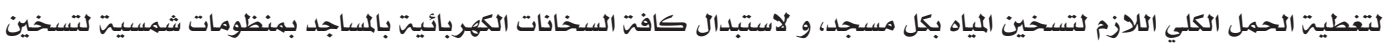
المياه يجب تركيب العدد الكايِّ من المنظومات الشمسيت لكل مسجد و هذا الأمر يقلل من الاعتماد على المصدر الكهربائي قدر الإمكان، كما يتطلب الأمر تركيب أجهزة قياس درجت الحرارة و عداد قياس الطاقت الكهربائيت و جهاز تحليل و تخزين بيانات و عداد قياس الحجهم على خطي دخول الماء البارد والماء الساخن لحنفيات الوضوء ذلك لإجراء دراست عمليت لقياس التوفير الناتج عن استبدال السخان الكهربائيت بالمستجد بمنظومت تسخين شمسيتة، و دراستّ نهط استهلاكت الماء الساخن بالمساجد.

\section{9. شكر و تقدير}

يتقدم مؤلفو هذه الورقت البحثيت بالثكر و التقدير للهيئتة العامت للأوقاف و الشؤون الإسلاميتّ و ذلك لحسن تعاونهم مـع الفريق

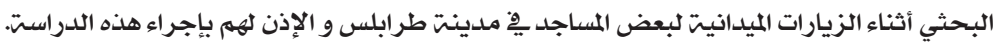


[1]-Abdunnabi M. M. A. Musa. Towards Strategic Plan for Wide Spreading of Solar Water Heaters in Libya. Journal of Solar Energy and Sustainable Development, JSESD, Vol (2), No (1), CSERS, 2013.

[2]-Abdunnabi M, K. Dadesh, O. R. Mrehel and N. El-shamekh. Effect of Full Implementation of Domestic Solar Water Heaters on the Electricity Peak Load in Libya., JSESD, Vol (5), No )2),CSERS, 2016.

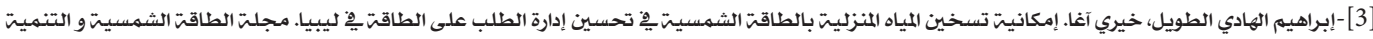

$$
\text { المستدامتة. المجلد (6). العدائ (1) (1). } 2017 .
$$

[4]-Alshrif Mustafa, M.A. Alghoul, Nilofar Asim. KH. Glaisa, KH. Abulqasem. M.N. Mohammed, A. Zaharim \& K. Sopian. "Potential of Renewable System Powering a Mosque in Libya. Models and Methods in Applied Sciences, pp: 139-144, ISBN: 978-1-61804-082-4.http://www.wseas.us/e_library/conferences/2012/SaintMalo/IAASAT/IAASAT-24.

[5]-Ahmed M. Saleh. Asmaddy Haris, Nursilah Ahmad. Towards a UTAUT-Based Model for the Intention to use Solar Water Heaters by Libyan Households. International Journal of Energy Economics and Policy Vol. 4, No. 1, 2014, pp.26-31.

[6]-Abdunnabi M, Abdulfatah A Idweib, Abdulghani M Ramadan. "Solar energy potential for hot water in the hotel sector in Libya". IREC2015 The Sixth International Renewable Energy Congress. IEEE, pp:1-5.2015.

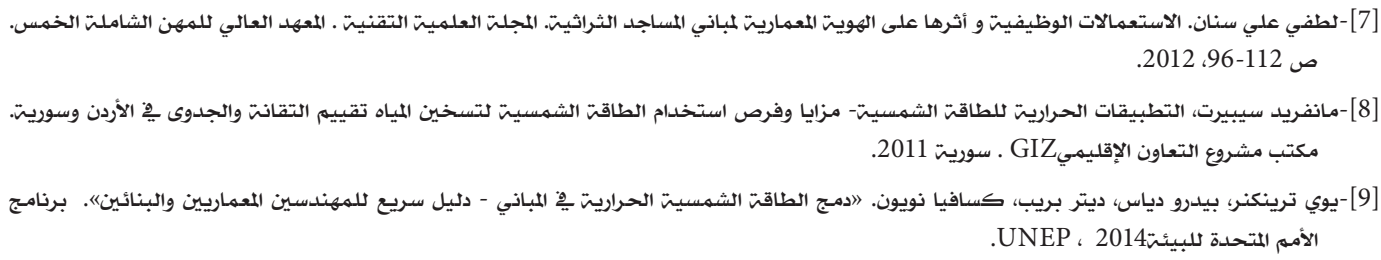

[10]-http://www.energy-design-tools.aud.ucla.edu/climate-consultant/download-climate-consultant.php.

[11]-EnergyPlus Weather of Tripoli City: https://energyplus.net/weather-download/africa_wmo_region_1/LBY//LBY_ Tripoli.620100_IWEC/LBY_Tripoli.620100_IWEC.epw.

[12]-D. Yogi Goswami. “Principles of Solar Engineering”. CRC Press, Taylor \& Francis Group, 3th ED, 2015.

[13]-Werner Platzer, Annabel Helmke, Jana Möllenbach, Simon Diekmann, Ilyes Ben Hassine, Franz Mauthner. "Overview and description of simulation tools for solar industrial process heat systems. IEA SHC Task 49 \& SolarPACES Annex IV Solar process heat for production and advanced applications, Deliverable C2, 2015. 